\title{
DESCONTAMINAÇÃO PRÉVIA DE MATERIAIS MÉDICO-CIRÚRGICOS: ESTUDO DA EFICÁCIA DE DESINFETANTES QUÍMICOS E ÁGUA E SABÃO
}

\author{
Adenícia Custódia Silva e Souza* \\ Milca Severino Pereira** \\ Márcia Alves Vasconcelos Rodrigues***
}

SOUZA, A.C.S.; PEREIRA, M.S.; RODRIGUES, M.A.V. Descontaminação prévia de materiais médico-cirúrgicos: estudo da eficácia de desinfetantes químicos e água e sabão. Rev.latino-am.enfermagem. Ribeirão Preto, v. 6, n. 3, p. 95-105, julho 1998 .

Estudo experimental, visando a comparar a eficácia da descontaminação prévia de materiais médico-cirúrgicos pelo uso de desinfetantes químicos e pela utilização de água, sabão e ação mecânica, e verificar a interferência da matéria orgânica nesse procedimento. Utilizaram-se como carreadores pinças cirúrgicas contaminadas com Staphylococcus aureus ATCC6538, Salmonella cholerae suis ATCC-10708 e Pseudomonas aeruginosa ATCC-15442, em presença e ausência de matéria orgânica (soro fetal bovino a 10\%). Empregaram-se cinco tratamentos: glutaraldeído 2\%, hipoclorito de sódio 1\%, peróxido de hidrogênio 6\%, álcool 70\% e, água, sabão e ação mecânica; com oito repetições, em um total de 480 observações. Nas condições testadas, os desinfetantes foram eficazes na descontaminação prévia de materiais médico-cirúrgicos e pouco inativados pela matéria orgânica. A limpeza mecânica com água e sabão apresentou redução dos microrganismos a níveis considerados adequados para descontaminação prévia.

UNITERMOS: infecção hospitalar, descontaminação prévia.

\section{INTRODUÇÃO}

Descontaminação é um termo usado para descrever um processo ou tratamento que torna um material hospitalar, instrumento ou superfície, seguro para o manuseio e uso. Um processo de descontaminação não significa, necessariamente, que este material está seguro para sua utilização no paciente, uma vez que o procedimento de descontaminação pode variar desde um processo de esterilização ou desinfecção até a simples lavagem com água e sabão (BLOCK, 1991).

Quando se emprega o termo descontaminação, o que usualmente vem à mente é apenas a primeira etapa de um processo de esterilização ou desinfecção, e como tal, denominado descontaminação prévia que além de tornar os materiais médico-cirúrgicos seguros para o manuseio, reduz consideravelmente seu bioburdem*****, tornando a desinfecção e esterilização mais fáceis, menos dispendiosas e com menor probabilidade de carrear material pirogênico.

A descontaminação prévia conhecida usualmente como desinfecção prévia tem sido realizada pela imersão dos materiais médico-cirúrgicos com presença de matéria orgânica, microrganismos e outros resíduos decorrentes do uso, em uma solução desinfetante por um tempo de exposição que varia de 15 a 30 minutos, objetivando-se a eliminação ou redução dos microrganismos presentes, antes de submetê-los à limpeza mecânica com água e sabão, com vistas a minimizar os riscos ocupacionais.

A limpeza mecânica com água e sabão, via de regra, realizada manualmente com auxílio de escova e com uso de equipamento de proteção individual (EPI), visa à remoção de todo material estranho como óleo, sangue, pus, fezes e outras secreções bem como a reduzir os microrganismos presentes nos materiais médicocirúrgicos.

A presença de matéria orgânica (sangue, secreções, pus ou fezes) pode interferir com a atividade antimicrobiana dos desinfetantes ou mesmo constituir-se numa barreira física de proteção aos microrganismos durante os processos de desinfecção e/ou esterilização por meios físicos ou químicos.

\footnotetext{
* Professor Assistente, Faculdade de Enfermagem/Universidade Federal de Goiás

** Professor Titular, Faculdade de Enfermagem/Universidade Federal de Goiás

*** Professor Adjunto, Instituto de Patologia Tropical e Saúde Pública/Universidade Federal de Goiás

**** Bioburdem - carga biológica, termo utilizado para designar a contaminação dos artigos médico-cirúrgicos durante o processo de fabricação ou após o uso
} 
A limpeza meticulosa dos materiais médicocirúrgicos, antes de submetê-los à desinfecção e/ou esterilização é um procedimento unânime e universal; as controvérsias ocorrem em relação ao momento da realização da limpeza e até mesmo na conceituação e compreensão do que seja limpeza e descontaminação.

Na prática clínica, há vários anos, tem-se usado este procedimento: após o uso, imerge-se o material em uma solução desinfetante por um tempo que varia de 15 a 30 minutos, depois procede-se à limpeza mecânica com água e sabão e destina-se o material à guarda, desinfecção ou esterilização, conforme a indicação de uso de cada um. Assim, promove-se a descontaminação prévia duas vezes, utilizando-se de métodos diferentes.

Questiona-se esse procedimento pelo fato de a maioria dos desinfetantes ser inativada pela matéria orgânica, podendo estar gerando uma "falsa" segurança, e ainda pelo desperdício de tempo, do próprio desinfetante e do desgaste do material (STIER et al.,1995).

A compreensão do que seja descontaminação, a diversidade e as controvérsias nos procedimentos técnicos, bem como a limitação dos desinfetantes utilizados para a imersão dos materiais antes da limpeza mecânica, evidenciam posicionamentos discordantes quanto à necessidade de uso de desinfetantes químicos na descontaminação prévia dos materiais médico-cirúrgicos, bem como, à atividade desses desinfetantes em presença de matéria orgânica.

Profissionais que executam este procedimento estão sempre questionando se a descontaminação prévia com água, sabão e ação mecânica é suficiente? ou se torna necessária a imersão desses materiais em solução desinfetante antes de se proceder a limpeza?

Na prática e na literatura existem defensores para os dois questionamentos, contudo, não se encontra na literatura, uma investigação na área microbiológica que garanta um cunho científico, na determinação desse procedimento.

A inexistência de indicações detalhadas e seguras à respeito da descontaminação prévia, pode estar levando ao desperdício de desinfetantes e tempo, além do desgaste e/ou corrosão precoce dos materiais e, principalmente, riscos ocupacionais e poluição ambiental.

$\mathrm{O}$ procedimento adequado para a descontaminação prévia dos materiais médico-cirúrgicos, bem como a determinação da interferência da matéria orgânica na atividade germicida dos desinfetantes químicos, são importantes na prevenção dos riscos ocupacionais, na garantia dos processos de desinfecção e esterilização e, principalmente, para oferecer um serviço de qualidade na assistência ao ser humano.
Este estudo tem como meta sugerir procedimentos seguros para a execução da descontaminação prévia, considerando, dentre outros aspectos, o fator tempo e economia hospitalar, através dos seguintes objetivos: comparar a eficácia da descontaminação prévia de materiais médico-cirúrgicos pela utilização de desinfetantes químicos e pelo uso de água, sabão e ação mecânica, através de análise bacteriológica e verificar a interferência da matéria orgânica nos desinfetantes utilizados na descontaminação prévia de materiais médico-cirúrgicos.

\section{MATERIAL E MÉTODOS}

Estudo realizado no laboratório de bacteriologia do Instituto de Patologia Tropical e Saúde Pública da UFG, no período de Fevereiro a Setembro de 1995.

- Carreadores: pinças cirúrgicas de aço inoxidável, novas e do mesmo tamanho (pinças hemostáticas, tipo Crile reta, $16 \mathrm{~cm})$.

- Tratamentos: Cinco tratamentos, sendo quatro pelo uso de desinfetantes (glutaraldeído 2\%; hipoclorito de sódio 1\%; peróxido de hidrogênio 6\% e álcool etílico 70\%) e um com água, sabão e ação mecânica (BRASIL/MS, 1993; RUTALA et al., 1993; TOLEDO et al.,1973; LARSON \& MORTON, 1991; TEIXEIRA \& PERACCINI, 1991).

- Neutralizantes: glutaraldeído 2\% - sulfito de sódio 0,1\%; hipoclorito de sódio $1 \%$-tiossulfato de sódio $0,5 \%$; peróxido de hidrogênio $6 \%$ - tiossulfato de sódio $0,6 \%$; álcool etílico 70\% - tween 80 (ROMÃO et al., 1991; LEME, 1990).

- Inóculos: Três microrganismos da coleção American Type Culture Collection: Staphylococcus aureus, ATCC $\mathrm{n}^{\circ}$ 6538; Salmonella cholerae suis, ATCC $\mathrm{n}^{\circ}$ 10708; Pseudomonas aeruginosa, ATCC no 15442 (CREMIEUX \& FLEURETE, 1991; ROMÃO et al. 1991).

- Matéria Orgânica: Soro fetal bovino (Laborclin) 10\% (CREMIEUX \& FLEURETE, 1991).

- Meios de Cultura: para o preparo da suspensão de bactérias - Caldo Mueller Hinton (MERCK); para a coleta do material - Caldo Letheen (DIFCO); para a contagem de colônias - Ágar para Contagem de Microrganismos em Placa (ISOFAR). (CREMIEUX \& FLEURETE,1991; ROMÃO et al., 1991; COLE et al., 1987). 


\section{- Delineamento e Condução do Experimento*}

\section{FIGURA 1: Fluxograma do delineamento do experimento}
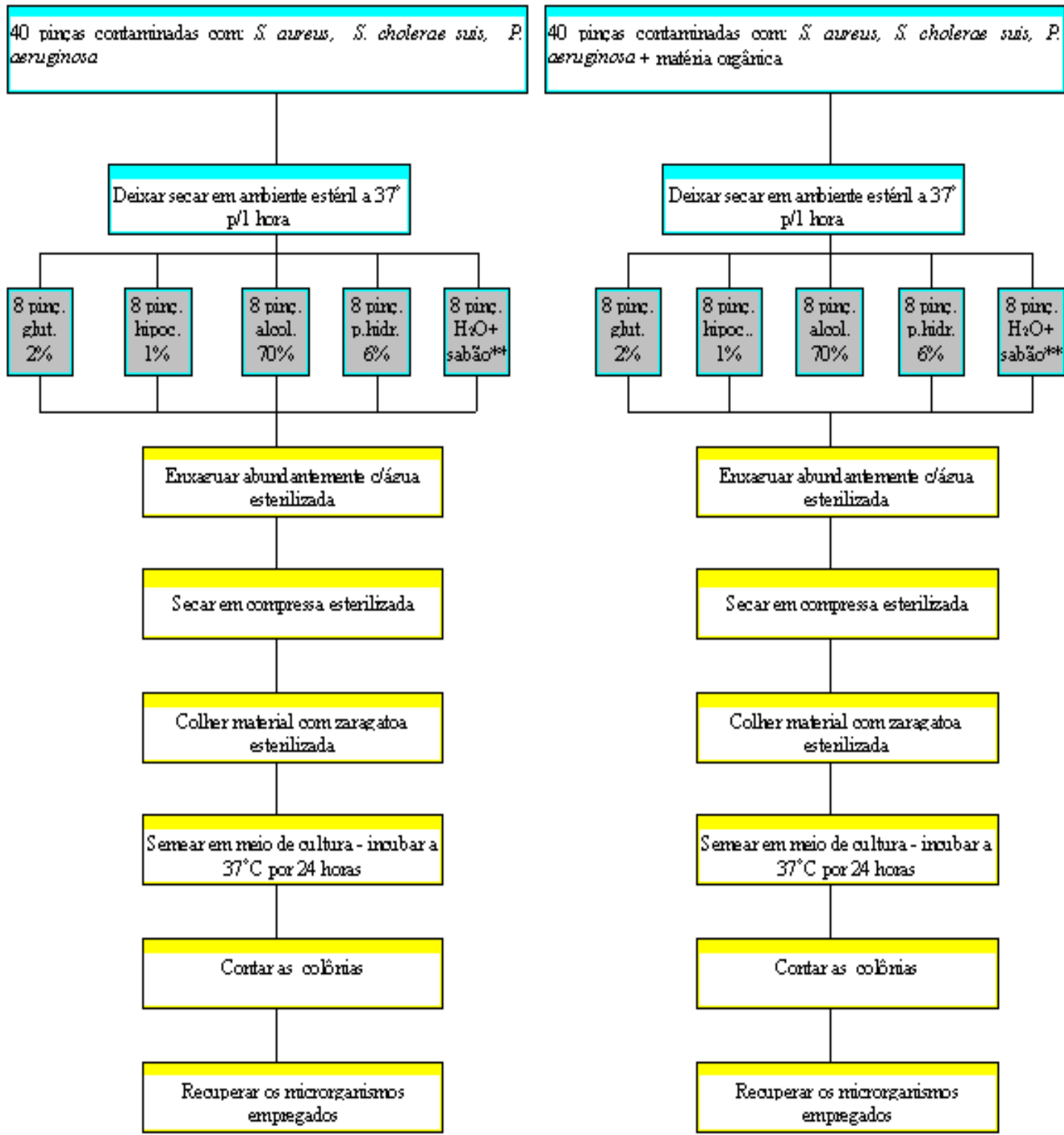

* Este fluxograma foi repetido para cada microrganismo teste

** E ação mecânica

O experimento teve um delineamento inteiramente casualizado que constou de cinco tratamentos com oito repetições cada.

Todas as etapas foram realizadas em câmara de fluxo laminar previamente lavadas com água e sabão e aplicada solução germicida de alto nível (glutaraldeído $2 \%)$.

Garantiram-se condições assépticas pelo uso de material esterilizado, lavagem das mãos, uso de luvas e máscara. Todo procedimento de coleta e plaqueamento foi realizado em zona asséptica.

A suspensão de bactérias foi preparada pela

adição da cultura de 48 horas, do inóculo a ser testado, no caldo Müeller Hinton até obter a concentração de 3,0 $\mathrm{X} 10^{8}$ por $\mathrm{ml}$, verificada pela turbidez comparada com o tubo número 1 da escala de McFarland. No grupo com matéria orgânica, esta foi acrescentada à suspensão logo após o seu preparo.

As pinças carreadoras foram imersas nesta suspensão tendo um período de contato de 15 minutos (ROMÃO et al., 1991; GELINAS \& GOULET, 1983).

Após esse período as pinças carreadoras foram colocadas na estufa a $37^{\circ} \mathrm{C}$ e permitido secar por uma hora (CREMIEUX \& FLEURETTE,1991). 
Terminado o processo de contaminação foi colhida amostra de uma pinça a fim de verificar adesividade e viabilidade dos inóculos; as demais foram submetidas aos tratamentos.

Os carreadores ficaram em contato com os desinfetantes (Glutaraldeído 2\%, Hipoclorito de sódio 1\%, Peróxido de hidrogênio 6\% e Álcool etílico 70\%) por um período de 30 minutos (BRASIL/MS, 1993; RUTALA, 1990).

Após o tempo de exposição aos desinfetantes, as pinças carreadoras foram enxaguadas por 10 agitações manuais em água esterilizada e mais 10 vezes por água esterilizada vertida de balão.

Para o tratamento com água, sabão e ação mecânica as pinças carreadoras foram lavadas através de 10 escovadelas para cada superfície e enxaguadas 10 vezes com água esterilizada vertida de balão. Após a enxaguadura permitiu-se a secagem das pinças carreadoras, por 15 minutos, sob compressas esterilizadas.

A coleta das amostras das pinças foi realizada pela técnica de Swab-rinse (McGOWAN \& WEISTEIN, 1992; McGOWAN, 1985; WEISTEIN \& MALLISON, 1978).

As zaragatoas foram embebidas no caldo de coleta, $5 \mathrm{ml}$ de Letheen, acrescido do neutralizante na concentração indicada para cada desinfetante e esfregadas suavemente, em toda a superfície da pinça carreadora, incluindo-se serrilhas, cremalheiras e articulações, por 3 vezes em movimentos sucessivos e direções inversas e recolocadas no tubo com caldo Letheen (FAVERO et al., 1984).

Terminado a coleta, cada tubo foi agitado, vigorosamente, batendo-o contra a palma da mão por 50 vezes, sendo 25 vezes de cada lado (FAVERO et al.,1984).

De cada amostra teste, após 5 agitações em movimentos circulares, foi semeado $0,5 \mathrm{ml}$ na superfície de placas com Ágar para Contagem de Microrganismos em Placa, utilizando-se pipetas.

As placas foram incubadas a $37^{\circ} \mathrm{C}$ por 24 horas. Após o período de incubação, procedeu-se à leitura pela contagem das colônias, que foram multiplicadas por 2 para se obter o resultado em unidades formadoras de colônias por $\mathrm{ml}(\mathrm{ufc} / \mathrm{ml})$.

Duas colônias de cada placa foram retiradas para fazer a coloração pelo Gram a fim de confirmar o microrganismo (McGOWAN, 1985). Para os Staphylococcus aureus foi realizado também a prova da catalase.

- Análise Estatística: Os resultados foram processados por computador através dos programas EPI- INFO e SAEG, utilizando-se análise de variância. Devido à grande variação nos resultados obtidos, estes foram transformados em logaritmo.
Das 41 pinças carreadoras, 40 foram submetidas a 5 tratamentos distintos, após os quais esperava-se uma redução de $75 \%$ dos microrganismos em relação ao inóculo inicial.

Considerando o Oddis Ratio $=8$ e $\propto=95 \%$, o STATCALC do EPI-INFO, versão 6.03 (jan/96) fornece$\operatorname{nos} u m n=40$ e um poder estatístico $\beta=80 \%$.

\section{RESULTADOS E DISCUSSÃO}

As variáveis microrganismos, tratamentos, matéria orgânica e o número de repetições e as duplicatas utilizadas neste estudo, permitiram 480 observações.

Devido a problemas estruturais e conjunturais o experimento foi dividido em vários grupos, de acordo com as variáveis microrganismo e matéria orgânica, sendo que a variável tratamento e o número de repetições foram comuns a todos.

Em todos os grupos garantiram-se as mesmas condições de temperatura, concentração e assepsia.

As pinças carreadoras foram contaminadas com uma suspensão de $300.000 .000\left(3,0 \times 10^{8}\right)$ de bactérias por $\mathrm{ml}$, contudo, não houve uma adesividade uniforme destes microrganismos às pinças carreadoras. A Tabela 1 evidencia o número em ufc/ $\mathrm{ml}$ de cada microrganismo empregado aderidos às pinças carreadoras na presença e ausência de matéria orgânica. Esses valores representam o inóculo inicial.

TABELA 1 - Crescimento de Staphylococcus aureus, Salmonella cholerae suis e Pseudomonas aeruginosa considerando a presença e ausência de materia orgânica em ufc/ml, do grupo controle (sem tratamento)

\begin{tabular}{|c|c|c|c|}
\hline Matéria Orgânía & $\begin{array}{c}\text { Staphylococcus } \\
\text { aureus }\end{array}$ & $\begin{array}{l}\text { Salmonella } \\
\text { cholerae suis }\end{array}$ & $\begin{array}{l}\text { Pseudomonas } \\
\text { aeruginosa }\end{array}$ \\
\hline Não & $\begin{array}{l}127.200 .000 \\
\left(1,27 \times 10^{\mathbf{2}}\right)\end{array}$ & $\begin{array}{c}71.700 .000 \\
\left(7,17 \times 10^{7}\right)\end{array}$ & $\begin{array}{l}143.100 .000 \\
\left(1,43 \times 10^{2}\right)\end{array}$ \\
\hline Sim & $\begin{array}{l}76.000 .000 \\
\left(7,60 \times 10^{7}\right)\end{array}$ & $\begin{array}{l}123.600 .000 \\
\left(1,24 \times 10^{3}\right)\end{array}$ & $\begin{array}{r}78.000 .000 \\
\left(7,80 \times 10^{7}\right)\end{array}$ \\
\hline
\end{tabular}

A análise feita por comparação pelo teste de Tukey e teste $t$. não evidenciou diferença significativa entre a adesividade dos diferentes microrganismos na presença ou não de matéria orgânica, embora haja variações na quantidade de microrganismos aderidos, tanto em relação à presença ou não de matéria orgânica quanto em relação aos microrganismos empregados.

De acordo com ROBISON et al. (1988) o número de organismos fixados aos carreadores é altamente dependente da espécie bacteriana utilizada.

Segundo COLE et al. (1987) esta variabilidade, presumivelmente, deve-se a características morfológicas 
e fisiológicas que afetam a aderência das bactérias. Num estudo interlaboratorial que realizaram com a finalidade de avaliar um método de padronização do número de bactérias em cilindros de aço inoxidável, encontraram uma variação no número de células nos cilindros de um mesmo laboratório e ainda entre os laboratórios para as três bactérias testadas (Staphylococcus aureus ATCC 6538, Salmonella cholerae suis ATCC 10708 e Pseudomonas aeruginosa ATCC 15442).

O tamanho do inóculo permite avaliar o número de sobreviventes após cada tratamento; na maioria dos métodos o nível requerido para um desinfetante corresponde a um decréscimo mínimo, de $10^{5}$ células por $\mathrm{ml}$ do inóculo inicial (CREMIEUX \& FLEURETE, 1991)

Os resultados obtidos com o uso de água, sabão e ação mecânica mostraram a presença dos três microrganismos empregados (Staphylococcus aureus, Salmonella cholerae suis e Pseudomonas aeruginosa) em todas as pinças carreadoras, porém, em número bem menor do que o utilizado para a contaminação inicial.

Quando as pinças carreadoras foram submetidas aos tratamentos com desinfetantes (glutaraldeído, 2\%; hipoclorito de sódio, $1 \%$; peróxido de hidrogênio, $6 \%$ e; álcool, 70\%), observou-se a eliminação dos microrganismos empregados na maioria das pinças carreadoras, e as poucas que evidenciaram crescimento, apresentaram grande variabilidade nesse número.

Em decorrência desse grande número de resultados zero nas amostragens de pinças carreadoras, tratadas com desinfetantes, não foi possível trabalhar esses dados estatisticamente, sua análise foi feita descritivamente.

Os resultados do tratamento com água, sabão e ação mecânica, permitiram avaliação estatística, sendo realizada através de análise de variância e teste t. Os dados foram processados por computador através dos programas EPI-INFO e SAEG. Devido à grande variação nos resultados obtidos, esses foram transformados em logaritmo para a análise.

TABELA 2 - Crescimento de Staphylococcus aureus considerando a presença e ausência de matéria orgânica em $\mathrm{ufc} / \mathrm{ml}$, após diferentes tratamentos

\begin{tabular}{|c|c|c|c|c|c|c|c|c|c|c|}
\hline \multirow{2}{*}{$\begin{array}{c}\text { TRATAMENTO } \\
\text { M. ORG }\end{array}$} & \multicolumn{2}{|c|}{$\begin{array}{c}\text { GLUTARALDÉ́DO } \\
\mathbf{2 \%}\end{array}$} & \multicolumn{2}{|c|}{$\begin{array}{c}\text { HIPOCLORTOO } \\
\text { DE SÓDIO } \\
1 \%\end{array}$} & \multicolumn{2}{|c|}{$\begin{array}{c}\text { PERÓXIDO } \\
\text { DE HIIROGẾNIO } \\
6 \% \\
\end{array}$} & \multicolumn{2}{|c|}{$\begin{array}{c}\text { ALCOOL } \\
70 \%\end{array}$} & \multicolumn{2}{|c|}{$\begin{array}{c}\text { ÁGUA, SABÃo } \\
\text { E AÇÃO MECÂNICA }\end{array}$} \\
\hline & NÃO & SIM & NÃO & SIM & NÃO & SIM & NÃo & SIM & NÃO & SIM \\
\hline 01 & 0 & 0 & 0 & 0 & 0 & 0 & 0 & 0 & 6 & 487 \\
\hline 02 & 0 & 0 & 2 & 4 & 0 & 0 & 0 & 0 & 20 & 131 \\
\hline 03 & 0 & 0 & 0 & 0 & 0 & 0 & 0 & 0 & 83 & 73 \\
\hline 04 & 0 & 0 & 45 & 2500 & 0 & 0 & 0 & 0 & 18 & 55 \\
\hline 05 & 0 & 0 & 2 & 0 & 0 & 0 & 0 & 0 & 13 & 22 \\
\hline 06 & 0 & 0 & 0 & 0 & 0 & 2500 & 0 & 0 & 12 & 47 \\
\hline 07 & 0 & 2 & 0 & 0 & 0 & 0 & 0 & 0 & 22 & 67 \\
\hline 08 & 4 & 0 & 0 & 10 & 0 & 0 & 0 & 54 & 14 & 43 \\
\hline TOTAIS & 4 & 2 & 49 & 2514 & 0 & 2500 & 0 & 54 & 188 & 925 \\
\hline
\end{tabular}

$\mathrm{ufc} / \mathrm{ml}=$ unidades formadoras de colônias por $\mathrm{ml}$.

M. org. = matéria orgânica

A maioria das pinças carreadoras contaminadas com Staphylococcus aureus e submetidas aos tratamentos com desinfetantes não evidenciou crescimento bacteriano, como demonstra a Tabela 2. Das 64 pinças carreadoras, apenas $10(15,6 \%)$ apresentaram crescimento e destas, 4 na ausência de matéria orgânica e 6 na presença de matéria orgânica.

Considerando que o inóculo inicial de Staphylococcus aureus em presença de matéria orgânica foi de $7,60 \times 10^{7}$ portanto menor do que na ausência de matéria orgânica que foi de $1,27 \times 10^{8}$ (Tabela 1) observa-se que os desinfetantes utilizados foram mais eficazes na ausência de matéria orgânica, que apesar de ter um inóculo maior, apresentou crescimento em apenas 4 pinças $(12,5 \%)$ e uma redução no número de microrganismos de $10^{7}$ células por $\mathrm{ml}$.

Os dados da Tabela 2 evidenciam também a interferência da matéria orgânica, principalmente, na ação do hipoclorito de sódio a $1 \%$ e peróxido de hidrogênio a $6 \%$ que permitiram crescimento bacteriano em 4 pinças, sendo que em 2 destas foi de $10^{3}$ células por $\mathrm{ml}$.

Estes dados, embora menores do que o esperado, concordam com estudos de alguns autores que relatam que a matéria orgânica protege os microrganismos do contato necessário com o germicida ou pode até mesmo inativar alguns deles (FAVERO \& BOND, 1991; PINHEIRO, 1990; GELINAS \& GOULET, 1983).

Os desinfetantes utilizados (glutaraldeído a $2 \%$, hipoclorito de sódio a $1 \%$, peróxido de hidrogênio a $6 \%$ e álcool a 70\%) apresentaram uma performance 
semelhante, evidenciando bom espectro de ação sobre os Staphylococcus aureus na ausência de matéria orgânica com um decréscimo de $10^{7}$ a $10^{8}$ células por $\mathrm{ml}$ em relação ao inóculo inicial.

Destaca-se a efetividade do álcool a $70 \%$ e do peróxido de hidrogênio a $6 \%$ que na ausência de matéria orgânica, eliminaram todos os microrganismos presentes nos carreadores. A ausência de crescimento no meio de cultura, significa que não havia microrganismos viáveis, presentes no material amostrado (PEELER \& MCCLURE, 1992).

No tratamento com água, sabão e ação mecânica houve redução no crescimento de Staphylococcus aureus de $10^{5}$ a $10^{6}$ células por $\mathrm{ml}$; evidenciando atender os níveis de redução requeridos para desinfecção. A análise feita pelos testes de Tukey e t. mostra que a variável matéria orgânica não interfere significativamente no resultado do tratamento com água, sabão e ação mecânica. Na prática, a ação mecânica é empregada de modo a remover toda a sujidade, independentemente, da quantidade de matéria orgânica aderida ao material, permitindo sua completa remoção.
A Tabela 3 mostra o crescimento de Salmonella cholerae suis após a instituição dos tratamentos. Chama atenção a inexistência de sobreviventes nos grupos com matéria orgânica, tratados com desinfetantes.

Observando o crescimento no grupo tratado com água e sabão, onde na verdade a eliminação dos microrganismos segundo FAVERO \& BOND (1991) não se faz por morte mas por remoção mecânica, também encontrou-se um número maior de crescimentos no grupo que não teve presença de matéria orgânica; embora estatisticamente não houve diferença significativa do tratamento na presença ou ausência de matéria orgânica.

Retomando os dados da Tabela 1 constata-se que a adesividade da suspensão contaminante de Salmonella cholerae suis às pinças carreadoras, ou seja, o inóculo inicial foi maior no grupo com presença de matéria orgânica, evidenciando que os desinfetantes utilizados (glutaraldeído a $\%$, hipoclorito de sódio a 1\%, peróxido de hidrogênio a $6 \%$ e álcool a $70 \%$ ) foram mais eficazes no grupo com presença de matéria orgânica apesar deste apresentar um inóculo inicial de $1,24 \times 10^{8}$ células por $\mathrm{ml}$, portanto, maior do que o apresentado pelo grupo sem matéria orgânica.

TABELA 3 - Crescimento de Salmonella cholerae suis considerando a presença e ausência de matéria orgânica em ufc/ml, após diferentes tratamentos

\begin{tabular}{c|c|c|c|c|c|c|c|c|c|c}
\hline TRATAMENTO & \multicolumn{2}{|c|}{$\begin{array}{c}\text { GLUTARALDEÍD } \\
\mathbf{2 \%}\end{array}$} & \multicolumn{2}{c|}{$\begin{array}{c}\text { HPOCORIO } \\
\text { DE SÓDIO } \\
\mathbf{1 \%}\end{array}$} & $\begin{array}{c}\text { PERÓXIDO DE } \\
\text { HIDROGÊNIO } \\
\mathbf{6 \%}\end{array}$ & \multicolumn{2}{c|}{$\begin{array}{c}\text { ALCOOL } \\
\mathbf{7 0 \%}\end{array}$} & \multicolumn{2}{c}{$\begin{array}{c}\text { AGUA, SABÃO } \\
\text { E AÇÃO MECÂNICA }\end{array}$} \\
\hline M. ORG. & NÃO & SIM & NÃO & SIM & NÃO & SIM & NÃO & SIM & NÃO & SIM \\
\hline 01 & 0 & 0 & 0 & 0 & 0 & 0 & 0 & 0 & 68 & 1953 \\
02 & 2 & 0 & 0 & 0 & 0 & 0 & 0 & 0 & 2962 & 248 \\
03 & 342 & 0 & 0 & 0 & 0 & 0 & 0 & 0 & 309 & 186 \\
04 & 0 & 0 & 0 & 0 & 10 & 0 & 0 & 0 & 194 & 1159 \\
05 & 0 & 0 & 0 & 0 & 0 & 0 & 2 & 0 & 836 & 100 \\
06 & 0 & 0 & 128 & 0 & 0 & 0 & 0 & 0 & 362 & 1953 \\
07 & 0 & 0 & 0 & 0 & 0 & 0 & 0 & 0 & 2546 & 437 \\
08 & 2500 & 0 & 0 & 0 & 0 & 0 & 0 & 0 & 1682 & 23 \\
\hline TOTAL & $\mathbf{2 8 4 4}$ & $\mathbf{0}$ & $\mathbf{1 2 8}$ & $\mathbf{0}$ & $\mathbf{1 0}$ & $\mathbf{0}$ & $\mathbf{2}$ & $\mathbf{0}$ & $\mathbf{8 9 5 9}$ & $\mathbf{6 0 5 9}$ \\
\hline
\end{tabular}

$\mathrm{ufc} / \mathrm{ml}=$ unidades formadoras de colônias por $\mathrm{ml}$.

M. org. = matéria orgânica

Observa-se ainda na Tabela 3 que dentre os desinfetantes utilizados como tratamento o peróxido de hidrogênio a $6 \%$ e o álcool a $70 \%$ foram os mais eficazes, apresentando uma redução de $10^{6}$ a $10^{8}$ células por $\mathrm{ml}$ em relação ao inóculo inicial.

A Tabela 4, a seguir, expõe o crescimento em $\mathrm{ufc} / \mathrm{ml}$, de Pseudomonas aeruginosa na presença e ausência de matéria orgânica, após os tratamentos com desinfetantes e água, sabão e ação mecânica, e mostra a eficácia dos desinfetantes utilizados sobre esse microrganismo, onde das 64 pinças carreadoras em apenas 4 delas $(6,25 \%)$ constatou-se a presença de crescimento e em pequeno número.

Destaca-se o fato de não haver crescimento nos grupos tratados com peróxido de hidrogênio a $6 \% \mathrm{e}$ álcool a 70\%. Reconhecidamente o peróxido de hidrogênio tem maior atividade sobre bactérias gram- negativas, do que sobre gram-positivas BLOCK (1991); e os organismos vegetativos gram-negativos são mais sensíveis à ação do álcool (LARSON \& MORTON, 1991). 
TABELA 4 - Crescimento de Pseudomonas aeruginosa considerando a presença e ausência de matéria orgânica em ufc/ml, após diferentes tratamentos

\begin{tabular}{|c|c|c|c|c|c|c|c|c|c|c|}
\hline \multirow{2}{*}{$\begin{array}{l}\text { TRATAMENTO } \\
\text { M.ORG. }\end{array}$} & \multicolumn{2}{|c|}{$\begin{array}{c}\text { GLUTARALDEÍDO } \\
\mathbf{2 \%}\end{array}$} & \multicolumn{2}{|c|}{$\begin{array}{c}\text { HIPOCLORITO } \\
\text { DE SÓDIO } \\
1 \%\end{array}$} & \multicolumn{2}{|c|}{$\begin{array}{c}\text { PERÓXIDO DE } \\
\text { HIIDROGÊNIO } \\
6 \%\end{array}$} & \multicolumn{2}{|c|}{$\begin{array}{c}\text { ÁLCOOL } \\
70 \%\end{array}$} & \multicolumn{2}{|c|}{$\begin{array}{c}\text { ÁGUA, SABÃo } \\
\text { E AÇÃ̃O MECÂNI } \\
\text { CA }\end{array}$} \\
\hline & NÃO & SIM & NÃO & SIM & NÃO & SIM & NÃO & SIM & NÄO & SIM \\
\hline 01 & 2 & 0 & 0 & 0 & 0 & 0 & 0 & 0 & 2 & 113 \\
\hline 02 & 0 & 0 & 0 & 0 & 0 & 0 & 0 & 0 & 28 & 804 \\
\hline 03 & 0 & 0 & 0 & 0 & 0 & 0 & 0 & 0 & 10 & 240 \\
\hline 04 & 0 & 0 & 2 & 0 & 0 & 0 & 0 & 0 & 287 & 20 \\
\hline 05 & 0 & 0 & 0 & 0 & 0 & 0 & 0 & 0 & 96 & 458 \\
\hline 06 & 0 & 0 & 0 & 0 & 0 & 0 & 0 & 0 & 2 & 4 \\
\hline 07 & 0 & 0 & 0 & 0 & 0 & 0 & 0 & 0 & 45 & 1092 \\
\hline 08 & 0 & 0 & 52 & 2 & 0 & 0 & 0 & 0 & 16 & 89 \\
\hline TOTAL & 2 & 0 & 54 & 2 & 0 & 0 & 0 & 0 & 486 & 2820 \\
\hline
\end{tabular}

$\mathrm{ufc} / \mathrm{ml}=$ unidades formadoras de colônias por $\mathrm{ml}$.

M. org. = matéria orgânica

A Tabela 4 mostra que a interferência da matéria orgânica na ação dos desinfetantes sobre Pseudomonas aeruginosa é mínima, evidenciando crescimento bacteriano, $2 \mathrm{ufc} / \mathrm{ml}$, em apenas um carreador tratado com hipoclorito de sódio a $1 \%$. Apesar do pequeno crescimento, isso confirma ser o hipoclorito de sódio o desinfetante que sofreu maior interferência da matéria orgânica.

Na instituição do tratamento com água, sabão e ação mecânica houve acentuada eliminação do microrganismo testado em relação ao inóculo inicial. Apesar de ter maior número de sobreviventes na presença de matéria orgânica, como mostra a Tabela 4, esta interferência não foi estatisticamente significante.

Embora este estudo não tenha objetivado verificar a eficácia dos desinfetantes; ao utilizá-los como parâmetro de comparação ao tratamento com água, sabão e ação mecânica, obteve-se o perfil dos 4 desinfetantes sobre os microrganismos testados.

Dentre os desinfetantes utilizados como tratamento, o álcool a 70\% apresentou espectro de ação dentro do requerido para a eficácia de um desinfetante, exibindo uma redução de $10^{6}$ a $10^{8}$ células por $\mathrm{ml} \mathrm{em}$ relação aos inóculos iniciais, na presença ou ausência de matéria orgânica.

O hipoclorito de sódio a $1 \%$ e peróxido de hidrogênio a $6 \%$ mostraram-se eficazes na ausência de matéria orgânica com um decréscimo que variou de $10^{5}$ a $10^{7}$ células por $\mathrm{ml}$. Esses dois desinfetantes receberam interferência da matéria orgânica na sua ação sobre Staphylococcus aureus, apresentando em apenas uma pinça um decréscimo de $10^{4}$ células por $\mathrm{ml}$, embora nas demais tenham tido eliminação total ou decréscimo de $10^{7}$ células por $\mathrm{ml}$.

O glutaraldeído a $2 \%$ que é um germicida de alto nível evidenciou um decréscimo de $10^{4}$ a $10^{8}$ células por $\mathrm{ml}$ sendo que o decréscimo de $10^{4}$ foi verificado no resultado de apenas uma pinça e na ausência de matéria orgânica.

Analisando-se as tabelas 2, 3 e 4, nota-se que a eficácia dos desinfetantes foi ligeiramente maior sobre os microrganismos gram-negativos do que sobre grampositivos, em especial o peróxido de hidrogênio a $6 \%$ e o álcool a $70 \%$ que mostram um decréscimo de $10^{6}$ a $10^{8}$ células por $\mathrm{ml}$ em relação aos inóculos iniciais das bactérias gram-negativas empregadas, independentemente, da presença ou não da matéria orgânica.

Em contrapartida a ação mecânica com água e sabão teve maior atividade sobre a bactéria gram-positiva empregada, exibindo um decréscimo de $10^{5}$ a $10^{7}$ células por $\mathrm{ml}$ em relação aos inóculos iniciais tanto em presença quanto em ausência de matéria orgânica.

A análise estatística realizada por comparação pelo teste de Tukey, mostra diferença na eficácia do tratamento com água, sabão e ação mecânica entre os microrganismos testados; sendo significantemente menor para Salmonella cholerae suis $(\mathrm{p}<0,05)$ do que para Pseudomonas aeruginosa e Staphylococcus aureus, e que apesar da diferença entre as médias do logaritmo de ufc/ml entre estes dois últimos microrganismos, esta não apresentou significância estatística.

Um dos objetivos deste estudo foi verificar a interferência da matéria orgânica na descontaminação prévia, uma vez que estudos de FAVERO \& BOND (1991); PINHEIRO (1990); GELINAS \& GOULET (1983) mostram que ela interfere de várias formas na ação dos germicidas. Os próprios fabricantes quando indicam no rótulo, se o germicida pode ser reusado e ou qual seu período de reuso, o faz mediante a atividade germicida do produto em presença de matéria orgânica. 
Apesar da baixa interferência da matéria orgânica sobre a ação dos desinfetantes na descontaminação prévia, evidenciada nesse estudo, esta se apresenta um pouco maior sobre microrganismos grampositivos.

Na realidade clínica diária não se conhecem os agentes infecciosos nem a quantidade deles presentes em cada material; o que se tem nos hospitais que possuem um serviço de controle de infecção hospitalar atuante é a incidência dos agentes infecciosos num determinado período e isso não exclui a presença de outros agentes.

Por outro lado, a matéria orgânica presente nesses materiais é bem conhecida e usualmente constituída por sangue, pus, fezes e óleos, normalmente distribuídos de forma e quantidade não uniformes.

Revela-se, portanto, necessário utilizar um desinfetante químico que tenha menor interferência da matéria orgânica e seja eficaz contra a maioria dos agentes infecciosos.

Os desinfetantes empregados neste estudo são comprovadamente eficazes, uma vez que reduziram os microrganismos-testes que são mais resistentes, apesar da matéria orgânica.

Na prática a desinfecção prévia, realizada com água, sabão e ação mecânica, potencializará as ações destes desinfetantes por permitir por si só, uma redução considerável dos microrganismos presentes nos materiais além de eliminar completamente a matéria orgânica.

O glutaraldeído, confirma sua boa atividade em presença de matéria orgânica, mesmo sobre grampositivos, como é amplamente conhecido e referenciado em manuais e normas técnicas de padronização de germicidas.

A surpresa fica por conta do hipoclorito de sódio que exibe baixa interferência da matéria orgânica, como visto nas tabelas 2,3 e 4 , pois sabidamente apresenta reduzida atividade germicida em presença de matéria orgânica, uma vez que o cloro livre reage com as proteínas da matéria orgânica, retendo algumas das atividades antibacterianas e reduzindo consideravelmente os níveis de cloro disponíveis. Essa perda de cloro é significantemente maior quando usado em pequenas concentrações (DYCHDALA, 1991; RUTALA, 1988).

Considera-se que a baixa interferência da matéria orgânica sobre os desinfetantes utilizados foi decorrente do uso de germicidas de níveis alto e intermediário em concentrações relativamente altas que apresentam uma reserva de segurança para realizar a requerida ação bactericida e, principalmente, pela utilização de soluções germicidas "virgens", sem reuso, o que confere maior atividade aos desinfetantes como germicidas, devido a garantia dos níveis de concentração do produto.

A interferência da matéria orgânica é maior em germicidas de baixo nível, em baixas concentrações e em soluções reusadas que vão gradativamente perdendo sua concentração e deixando menor quantidade de germicida ativo disponível para atacar os microrganismos (DYCHDALA, 1991; BLOCK, 1991; LARSON \& MORTON, 1991; FAVERO \& BOND, 1991).

Discute-se, também, que o tipo e quantidade de matéria orgânica tem um papel importante na ação dos desinfetantes (PINHEIRO, 1990; ROBISON et al., 1988). Nesse estudo testou-se apenas um tipo de matéria orgânica, soro fetal bovino, que corresponde ao sangue humano, sabidamente a matéria orgânica mais presente nos materiais médico-cirúrgicos.

Este estudo analisa a interferência da matéria orgânica em soluções germicidas sem reuso, porém, na prática reutilizam-se soluções germicidas num período que varia de 24 horas até 28 dias, conforme especificação do fabricante para cada germicida sem, contudo, dispor de testes que viabilizem a verificação do nível de concentração de cada desinfetante para reuso.

A utilização de germicidas químicos na descontaminação prévia, deve ser observada com cautela, pois vários deles são gradativamente inativados pelos resíduos acumulados na solução e de acordo com LACERDA et al. (1992) na prática ainda não existem estudos que demonstrem quando e qual quantidade de resíduos são suficientes para neutralizar a ação dos germicidas.

A Tabela 1 mostra que nas pinças controles, sem tratamento, não houve diferença significativa entre as médias de adesividade dos diferentes microrganismos na presença ou ausência de matéria orgânica quando comparados pelo teste de Tukey.

Embora se verifique presença de microrganismos em todas as pinças carreadoras tratadas com água, sabão e ação mecânica, houve um decréscimo de $10^{4}$ a $10^{6}$ células por $\mathrm{ml}$, em relação aos inóculos iniciais, tendo maior eficácia $(\mathrm{p}<0,05)$ sobre Pseudomonas aeruginosa e Staphylococcus aureus, sendo que não houve diferença significante entre presença ou não de matéria orgânica no tratamento com água, sabão e ação mecânica. É bom lembrar que nesse estudo a ação mecânica com água e sabão foi aplicada sobre microrganismos e matéria orgânica secos sobre os carreadores, o que torna mais difícil sua eliminação. Sabe-se que essa eliminação pode ser bem maior quando o instrumental é colocado em imersão na água e sabão imediatamente após o uso.

O potencial patogênico das bactérias depende da capacidade que possuem em invadir, sobreviver e se multiplicar no tecido hospedeiro, em inibir os mecanismos de defesa deste e em causar danos séricos pela destruição tecidual; e o nível crítico necessário para causar infecção varia de $10^{2}$ a $10^{5}$ bactérias por grama de tecido ou por $\mathrm{ml}$ de fluido biológico FERNANDEZ et al. (1994); ALTEMEIER (1988). Os resultados encontrados 
mostram que até mesmo o maior número de ufc $/ \mathrm{ml}$ apresentado no tratamento com água, sabão e ação mecânica, não é suficiente para provocar uma infecção nos profissionais que manuseiam estes instrumentais, principalmente, considerando-se que devem estar hígidos e com integridade de suas barreiras naturais de proteção antiinfecciosa.

Isso significa que, após a ação mecânica com água e sabão, o instrumental é considerado seguro para o manuseio e pronto para ser processado por desinfecção e/ou esterilização, conforme indicação de uso dos instrumentos.

Tornar os materiais médico-cirúrgicos seguros para manuseio e com pequena carga microbiana, são as principais metas da descontaminação prévia, pois quanto menor o número de microrganismos presentes no material a ser processado por desinfecção e/ou esterilização, melhor será o resultado final destes processos e isso demonstra garantia da qualidade da desinfecção e/ou esterilização.

\section{CONCLUSÃO}

Os desinfetantes (glutaraldeído, 2\%; hipoclorito de sódio, $1 \%$; peróxido de hidrogênio, $6 \%$ e; álcool, $70 \%$ ) utilizados neste estudo, receberam pouca interferência da matéria orgânica ( $10 \%$ de soro fetal bovino) e foram eficazes na descontaminação prévia.

Os microrganismos-testes, apresentaram comportamentos diferentes, frente a ação dos desinfetantes em presença de matéria orgânica. Enquanto a matéria orgânica não interferiu na ação dos desinfetantes sobre os microrganismos Gram-negativos, os desinfetantes sofreram interferência da matéria orgânica, na sua ação sobre os microrganismos Gram-positivos, nas condições testadas.

Apesar de haver crescimento bacteriano em todas as pinças carreadoras, tratadas com água, sabão (desencrostante) e ação mecânica, a redução dos microrganismos em relação ao inóculo inicial, foi bastante significativa, mostrando atender os objetivos da descontaminação prévia.

Observa-se que, tanto os desinfetantes nas condições testadas, quanto a ação mecânica com água e sabão, cumprem sua finalidade na descontaminação prévia, que é de reduzir o número de microrganismos, facilitando a desinfecção e/ou esterilização e conferindo maior segurança para o manuseio.

A descontaminação prévia com desinfetantes químicos, embora reduza consideravelmente o número de microrganismos, não remove a sujeira do material, exigindo uma segunda etapa no processo de descontaminação, que é a limpeza através da ação mecânica com água e sabão.

O uso de desinfetantes químicos na descontaminação prévia, além de exigir uma segunda etapa para a conclusão deste processo, torna-o mais dispendioso, exige maior tempo, devido ao tempo de exposição necessário para os desinfetantes exercerem suas ações germicidas; expõe o material a produtos que podem corroê-los com o tempo e, ainda, oferece riscos ocupacionais.

A descontaminação prévia, através da limpeza pela ação mecânica com água e sabão, mostra-se eficaz e é realizada num único momento, cumprindo as duas finalidades: eliminação da sujeira e redução dos microrganismos.

A limpeza mecânica com água e sabão, torna-se muito mais efetiva através de lavadoras automáticas, além de apresentar menor risco ocupacional. Outro fator à favor das lavadoras automáticas é que algumas delas utilizam água em altas temperaturas conferindo além de limpeza, uma desinfecção física.

Contudo, a realidade evidencia que a maioria dos hospitais, não possui estas máquinas lavadoras e prédesinfectoras, gerando a necessidade de se ter alternativas confiáveis como a limpeza mecânica manual, que garantam a execução desse procedimento.

A indicação de que tanto a limpeza mecânica com água e sabão quanto os desinfetantes utilizados mostraram-se eficazes na descontaminação prévia de materiais médico-cirúrgicos, deixa alternativa de escolha aos profissionais que executam esse procedimento.

Considerando a economia de tempo, de material de consumo e recursos humanos e, ainda, a conservação dos materiais médico-cirúrgicos e a alta rotatividade desses materiais, a opção recai sobre o uso de água, sabão e ação mecânica para a descontaminação prévia. Contudo, se em algumas situações específicas julgar-se conveniente, pode-se lançar mão dos desinfetantes para esse procedimento.

\section{PREVIOUS DESCONTAMINATION OF THE MEDICAL SURGICAL MATERIALS: STUDY OF THE EFFICIENCY OF CHEMICAL DISINFECTANTS AND WATER AND SOAP}

In this experimental study we compared the previous descontamination efficacy of the medical surgical materials by the use of chemical disinfectants and the mechanical cleaning with water and soap, as well as verified the organic material interference in these procedures. To carry out this study, we used surgical pincers under contamination with: Staphylococcus aureus ATCC-6538, Salmonella cholerae suis ATCC-10708, and Pseudomonas aeruginosa ATCC-15442 in presence and 
absence of organic matter (fetal bovine serum). The following treatments: glutaraldehyde $2 \%$, sodium hypochlorite $1 \%$, hydrogen peroxide $6 \%$, alcohol $70 \%$ and the mechanical cleaning with water and soap were compared with eight repetitions in a total of 480 observations. In the described conditions, the disinfectants had a good efficacy in the previous descontamination of the medical surgical materials and a less inativation by the organic material. The mechanical cleaning with water and soap showed a reduction of the microrganism to safe levels, considered adequate for previous descontamination.

KEY WORDS: nosocomial infection, previous descontamination

\section{DESCONTAMINACIÓN PRÉVIA DE LOS INSTRUMENTOS MÉDICO-QUIRÚRGICOS: ESTUDIO DE LA EFICACIA DE DESINFECTANTES QUÍMICOS Y AGUA Y JABÓN}

Estudio experimental, dirigido a comparar la eficacia de la descontaminación previa de instrumentos médico-quirúrgicos por el uso de desinfectantes químicos y de agua, jabón y acción mecánica, y vereificar la interferencia de la materia orgánica en ese procedimento. Se utilizaron como vehículos, pinzas quirúrgicas contaminadas con Staphylococcus aureus ATCC-6538, Salomella choleras suis ATCC-10708 y Pseydomonas aeruginosa ATCC-15423, en presencia y ausencia de materia orgánica (suero fetal bovino, 10\%). Se emplearon cinco tratamientos: glutaraldeído 2\%, hipoclorito de sodio $1 \%$, peróxido de hidrógeno 6\%, alcohol 70\% y agua, jabón y acción mecánica; con ocho repeticiones, en un total de 480 observaciones. En las condiciones probadas, los desinfectantes fueron eficaces en la descontaminación previa de instrumentos médico-quirúrgicos y poco inactivados por la materia orgánica. La limpieza mecánica con agua y jabón, presentó redución de microorganismos a niveles considerados adecuados para descontaminación previa.

TÉRMINOS CLAVES: Infección hospitalaria, descontaminación previa

\section{REFERÊNCIAS BIBLIOGRÁFICAS}

01. ALTEMEIER, W.A. et al. Manual de controle de infeç̧ão em pacientes cirúrgicos. Trad. Ana Carolina Vasques Giovanoli. São Paulo: Roca, 1988.394p.

02. BLOCK, S. S. Disinfection, sterilization, and preservation. 4 ed. Philadelphia: Lea \& Febiger, 1991.p.167-81. Peroxigen compounds.

03. BRASIL. Ministério da Saúde. Coordenação de Controle de Infecção Hospitalar. Processamento de artigos e superfícies em estabelecimentos de saúde. Brasília, 1993. $32 p$.

04. COLE, E.C. et al. Standardization of bacterial numbers on penicylinders used in disinfectant testing: Interlaboratory study. J. Assoc. Off. Anal. Chem.., v.7, n.4, p.635-37, 1987.

05. CREMIEUX, A.; FLEURETTE, J. Methods of testing disinfectants. In: BLOCK, S. S. Disinfection, sterilization, and preservation. 4 ed. Phyladelphia: Lea \& Febiger, 1991.p.100927.

06. DYCHDALA, G.R. Chlorine and chlorine compounds. In: BLOCK, S.S. Disinfection, sterilization, and preservation. 4. ed. Philadelphia: Lea \& Febiger, 1991.p.131-51.

07. FAVERO, M.S., BOND,W.W. Sterilization, disinfection, and antisepsis in the hospital. In: Manual of clinical microbiology. Washington DC: American Society for Microbiology, 1991. p.183-200.
08. FAVERO, M.S.et al. Environmental monitoring procedures. In: SPECK, M. L. Compendium of methods for the microbiological examination of foods. 2 ed. Washington, D.C: American Public Health Association, 1984. p.47-61.

09. FERNANDEZ, A. et al. Profilaxis quirurgica. Bol. Hosp. San Juan Dios (Chile), v.41, n.1, p.2227, 1994.

10. GELINAS, P.; GOULET, J. Neutralization of the activity of eight disinfectants by organic matter. J. Appl. Bacteriol., n.54, p.243-47, 1983.

11. LACERDA, R.A. et al. Buscando compreender a infeç̧ão hospitalar no paciente cirúrgico. São Paulo: Atheneu, 1992. p.101-13.

12. LARSON, E.L.; MORTON, H.E. Alcohols. In: BLOCK, S.S. Disinfection, sterilization, and preservation. 4 ed. Philadelphia: Lea $\&$ Febiger, 1991.p.191-202.

13. LEME, M.T.C.L. Flashes em controle de infecção. Curitiba: Relisul, 1990. 269p.

14. McGOWAN, J.E.J. Role of the microbiology laboratory in prevention and control of nosocomial infection. In: LENNETTE, E.H. et al. Manual of clinical microbiology. 4 ed. Washington,D.C.: American Society for Microbiology, 1985. p.11022.

15. McGOWAN, J.E.J., WEINSTEIN, R.A. The role of the laboratory in control of nosocomial infection. In: BENNETT, J.V.; BRACHMAN, P.S., SANFORD,J.P. Hospital infections. 3 ed. Boston: Little, Brown, 1992. p.187-220. 
16. PEELER, J.T.; MCCLURE, F.D. Most probable number determination. Apendix 2. In: FOOD and drug administration: bacteriological analytical manual. 7. ed. Arlington: AOAC International, 1992. Cap.25, p.439-52.

17. PINHEIRO, S.R. Influência da matéria orgânica na atividade micobactericida de cinco desinfetantes de uso pecuário. São Paulo, 1990. 43p. Dissertação (Mestrado) - Faculdade de Medicina Veterinária e Zootecnia, Universidade de São Paulo.

18. ROBISON, R.A. et al. A suspension method to determine reuse life of chemical disinfectants during clinical use. Appl. Environ. Microbiol., v.54, n.1, p.158-64, 1988.

19. ROMÃO, C.M.C. et al. Manual de saneantes: métodos para análise microbiológica de saneantes com ação antimicrobiana. Rio de Janeiro: Fundação Oswaldo Cruz. Instituto Nacional de Controle de Qualidade em Saúde, 1991. 62p.
20. RUTALA, W.A. Draft Guideline for selection and use of disinfectants. Am. J. Infect. Control, v.17, n.1, p.25A-38A, 1988.

21. RUTALA, W.A. Apic guidelines for selection and use of disinfectants. Am. J. Infect. Control, v.18, n.2, p.99-117, 1990.

22. RUTALA, W.A. et al. Sporicidal activity of chemical sterilants used in hospitals. Infect. Control Hosp. Epidemiol., v.14, n.12, p.713-18, 1993.

23. STIER, C.J.N. et al. Rotinas em controle de infecção hospitalar. Curitiba: Netsul, 1995. 196p.

24. TEIXEIRA, O.L.S.; PERACCINI, M.H. Limpeza hospitalar. Rev. Hosp. Adm. Saúde, v.15, n.2, p.66-70, 1991.

25. TOLEDO, R.T. et al. Sporicidal properties of hydrogen peroxide against food spoilage organisms. Appl. Microbiol., v.26, n.4, p.592-97, 1973.

26. WEINSTEIN, R.A.; MALLISON, G.F. The role of the microbiology laboratory in surveillance and control of nosocomial infections. Am. J. Clin. Pathol., n.69, p.130-6, 1978. 